\title{
Endocrine Therapy for Male Breast Cancer
}

\section{Ian S Fentiman*}

Professor of Surgical Oncology, Research Oncology, Guy's Hospital, London, UK

\begin{abstract}
More than $90 \%$ of male breast cancers (MBC) are estrogen receptor positive but unfortunately over $40 \%$ are either stage III or stage IV at the time of presentation. This means that for a substantial proportion of patients, endocrine therapy will be used in a palliative role in the management of MBC. Tamoxifen is the main first line agent that is given for both adjuvant treatment and control of advanced disease. Although effective it can be more toxic in men than in women so that a significant proportion of males will become non-compliant. It is important that non-adherence is recognised and whenever possible second line therapy is instituted with either aromatase inhibitors or LHRH analogues. International collaboration in randomised trials will be necessary to determine the future endocrine therapies for MBC.
\end{abstract}

Keywords: Male breast cancer; Immunohistochemistry; Estrogen receptor; Progesterone receptor

\section{Introduction}

Male breast cancer $(\mathrm{MBC})$ is a rare disease comprising $<1 \%$ of total cases. As such, single institutions have been unable to amass sufficient patients for inclusion in prospective randomised trials so that clinical practice has been largely determined by experience with female breast cancer. In order to develop rational therapies it is important to understand the similarities and differences between breast cancers in women and men.

\section{Risk Factors}

Data on risk factors for male breast cancer has been largely derived from retrospective studies which can be biased by selective recall. To overcome this problem Brinton et al. studied 324920 male participants in the prospective National Institutes of Health -AARP Diet and Health Study [1]. Of this cohort, 121 were subsequently diagnosed with MBC. Obesity was positively associated with risk $(\mathrm{RR}=1.79)$ as was a prior history of bone fracture, $(\mathrm{RR}=2.20)$. The authors postulated that risk factors in men may result from unique mechanisms associated with the ratio of androgens and bioavailable estrogens.

In subsequent work Brinton et al. [2] accessed 26 million hospital discharge records on the US Veterans Affairs database for the period 1969-1996. From 4,501,578 men aged 18-100 years, 642 MBC cases were identified. Several diseases were associated with increased risk including diabetes $(R R=1.30)$, obesity $(R R+1.98)$, orchitis/epididymitis $(\mathrm{RR}=1.84)$, and Klinefelter syndrome $(\mathrm{RR}=29.64)$.

\section{Prognosis}

Anderson et al. [3] examined the National Cancer Institute's Surveillance, Epidemiology, and End Results (SEER) program for male and female breast cancers diagnosed between 1973 and 2005. They reported that deaths from breast cancer declined over time. Comparing 1976-85 with 1986-2005, for women cause-specific hazard rates reduced by $42 \%$ compared with only $28 \%$ in men.

Gnerlich et al. [4] conducted a retrospective cohort study to investigate breast cancer-specific and all-cause mortality between males $(1,541)$ and females $(244,518)$ using 1988-2003 SEER Program data. Males were more likely to be older, have more advanced cancers, but have tumours of lower grade which were mostly estrogen/progesterone receptor positive. After adjustment, men had higher breast cancer specific mortality only if diagnosed with stage I disease.
In a large international study, Miaio et al. [5] analysed data from Denmark, Finland, Geneva, Norway, Singapore, and Sweden which included 459,846 women and 2,665 men with breast cancer. Standardised incidence rates were 66.7 per 105 person-years in women and 0.40 in men. Median ages at diagnosis were 61.7 and 69.6 years respectively. Although males had a worse 5-year relative survival ratio $(0.72 v 0.78)$ after adjustment for age, stage, and treatment, they had a significantly better relative survival.

Another gender comparison from the Veterans Affairs (VA) Central Cancer Registry (VACCR), examined survival of 612 patients with MBC and 2413 with FBC [6]. Mean ages at diagnosis were 67 and 57 years respectively. Males had higher stage of disease and greater likelihood of nodal involvement. Median overall survivals were 7 and 9.8 years respectively. In contrast, for those with stage I/II disease the median survivals differed significantly. Node-negative males had a median survival of 6.1 years whereas for females it was 14.6 years. Median survival was similar in lymph node-positive patients of both genders. In multivariate analysis age, sex, stage, and nodal status were independent prognostic factors but tumour type and grade were not.

\section{Male Breast Tumour Molecular Profiling}

Molecular subtyping by gene expression in female breast cancer has been extensively investigated, with more recently data on $\mathrm{MBC}$ becoming available and these are summarised in Table 1 . Ge et al. [7] used immunohistochemistry (IHC) for estrogen receptor (ER), progesterone receptor (PR), cytokeratin 5/6 (CK5/6), EGFR, and NF$\kappa \mathrm{B}$, Human epidermal growth factor receptor 2 (HER2) expression to subtype $42 \mathrm{MBC}$ tumours. The luminal a subtype was the most common subtype $(83 \%, 35 / 42)$, followed by luminal B subtype (17\%, 7/42). There were no basal-like and HER2+/ERsubtypes identified. All tumours were ER +ve and $67 \%$ were PR+. High nuclear grades represented $71 \%$ of the luminal B subtype and $34 \%$ of luminal A subtype $(34 \%, 12 / 35)$.

*Corresponding author: Ian S Fentiman, Professor of Surgical Oncology Research Oncology, 3rd Floor Bermondsey Wing, Guy's Hospital, London SE1 9RT, UK, Tel: 00442071887188; E-mail: ian.fentiman@gstt.nhs.uk

Received May 02, 2013; Accepted June 06, 2013; Published June 21, 2013

Citation: Fentiman IS (2013) Endocrine Therapy for Male Breast Cancer. J Steroids Horm Sci 4: 112. doi:10.4172/2157-7536.1000112

Copyright: (C) 2013 Fentiman IS. This is an open-access article distributed unde the terms of the Creative Commons Attribution License, which permits unrestricted use, distribution, and reproduction in any medium, provided the original author and source are credited. 


\begin{tabular}{|c|c|c|c|c|c|c|c|}
\hline Author & $\mathbf{N}$ & ER +ve & PR +ve & HER2 +ve & Luminal A & Luminal B & Basal-type \\
\hline Ge et al. [7] & 42 & $100 \%$ & $67 \%$ & $17 \%$ & $83 \%$ & $17 \%$ & 0 \\
\hline Sánchez-Muñoz et al. [9] & 43 & $93 \%$ & $84 \%$ & 0 & $44 \%$ & $51 \%$ & $5 \%$ \\
\hline Deb et al. [10] & 60 & $90 \%$ & $77 \%$ & $9 \%$ & $89 \%$ & $9 \%$ & $2 \%$ \\
\hline Johansson et al. [11] & 286 & $88 \%$ & $73 \%$ & $8 \%$ & M1 70 M2 30\% & & \\
\hline Kornegoor et al. [12] & 134 & $94 \%$ & $68 \%$ & $3 \%$ & $76 \%$ & $21 \%$ & \\
\hline Nilsson et al. [13] & 197 & $93 \%$ & $77 \%$ & $11 \%$ & $81 \%$ & $11 \%$ & $1 \%$ \\
\hline
\end{tabular}

Table 1: Molecular subtyping of MBC.

This suggests that both pathology and aetiology are different in males and females.

In a multi-centre study, Shaaban et al. compared 251 male and 263 female breast cancers, matched for grade, age, and lymph node status. Tissue microarrays were immunostained for ERa, ER $\beta 1,-2,-5$, PR, PRA [8]. In both sexes luminal A was the commonest phenotype with luminal B and HER2 not seen in males and basal phenotype was infrequent in both. AR-positive luminal A male breast cancer had improved overall survival over female breast cancer at 5 but not 10 years. In a relatively small Spanish series Sanchez-Munoz reported that 6-year survival in men with luminal A and luminal B tumours was similar [9].

Deb et al. [10] studied 60 cases of familial MBC of whom 3 were BRCA1 and 25 BRCA2 mutation carriers. In contrast to FBC) there was greater proportion of BRCA2 tumours ( $42 \%$ versus $8 \%$, and fewer BRCA1 tumours $(5.0 \%$ versus $14 \%$. The histological subtypes seen in familial $\mathrm{MBC}$ were more similar to those seen in sporadic $\mathrm{MBC}$ with 77\%) being invasive ductal carcinoma of no special type (IDC-NST). Most tumours were of the luminal phenotype (89\%), a few were HER2 (9\%) and rarely basal (2\%).

Using unsupervised hierarchical clustering (HCL) Johansson et al. studied gene expression in 66 frozen MBC specimens and separated them into two subtypes, luminal M1 and luminal M2 [11]. This separation was recapitulated in a validation set of 220 archival MBCs. M1 tumours, although ER +ve, expressed fewer genes associated with ER signalling and had a more aggressive phenotype and a worse prognosis. M2 tumours had higher expression of both immune response genes and ER signalling genes.

Of the most differentially expressed genes, class 1 human leukocyte antigen (HLA) and the metabolizing gene $\mathrm{N}$-acetyltransferase-1 (NAT1), there was significantly better survival associated with high expression of both. On multivariate analysis, NAT1 retained significance suggesting that it is a prognostic marker in MBC.

Kornegoor et al. studied 134 MBC using immunohistochemistry stained on tissue microarrays for expression of multiple markers including ER, PR, AR, HER2, p53, Ki67, and EGFR [12]. In unsupervised HCL, four groups were delineated that associated with particular clinicopathological features. The groups were: A1, hormonenegative; A2, ER-positive high grade; B1, ER-positive intermediate grade; B2, ER-positive low grade. Of the individual prognostic markers $\mathrm{PR}$ and $\mathrm{p} 53$ were the most promising.

Nilsson et al. [13] reviewed paraffin-embedded tumour tissue from 197 MBC patients and used tissue microarrays and grading of $\mathrm{H}$ and $\mathrm{E}$ stained slides. Of the tumours, $93 \%$ were ER+VE and $77 \% \mathrm{PR}+\mathrm{ve}$, with $41 \%$ being grade III and $11 \%$ HER $2+$ ve. Using IHC markers $81 \%$ were luminal $\mathrm{A}$ and $11 \%$ luminal $\mathrm{B}$. There were 2 basal-like cancers and no HER2-like tumours. There was no difference in breast cancer mortality between the luminal subgroups. Androgen receptor positivity has been reported in 39-95\% of MBC specimens but no association with clinicopathological features or prognosis has been reported [14,15]. All of these disparate results clearly indicate that $\mathrm{MBC}$ is a predominantly estrogen dependent disease.

Until now the only molecular targeting for male breast cancer has been either endocrine therapies in those with ER + ve cancers and herceptin or lapatanib for the few with tumours over-expressing HER2 [16]. As molecular profiling moves from a research tool to a prognostic system so it is hoped that specifically targeted regimens for specific groups can be tested.

\section{Historical Endocrine Treatments for MBC}

Over $40 \%$ of MBC present with stage III/IV disease so that treatment is often palliative rather than curative [17]. After Beatson had shown that oophorectomy could achieve remissions in advanced breast cancer [18] so orchidectomy became first line treatment for MBC. Before the discovery of estrogen receptors a response rate of approximately $30 \%$ was seen in men with advanced disease [19]. Although orchidectomy could be effective in palliation it was not an option that was acceptable to many with MBC.

In 1978, Cantwell et al. [20] reported a series of three cases of MBC that had been treated with the selective estrogen receptor modulator (SERM) tamoxifen. All three patients went into remission, two of them for more than a year. Subsequently Kantarjian et al. [19] showed that first line tamoxifen was as effective tamoxifen after orchidectomy so that men could be spared the psychological distress of castration. Furthermore tamoxifen could be used as an adjuvant treatment as well as a palliative therapy for advanced disease.

\section{Adjuvant Therapy for MBC}

The rarity of $\mathrm{MBC}$ has meant that randomised trials of adjuvant endocrine therapy for MBC have not been conducted. Assumptions have been made concerning treatments for $\mathrm{MBC}$ based on extrapolation from results of trials conducted for women with breast cancer. The first reported study of adjuvant tamoxifen for MBC was that of Ribeiro and Swindell who treated 39 men [21]. Tamoxifen was originally given for 1 year and subsequently extended to 2 years. All cases had clinical axillary nodal involvement and surgery was either a radical mastectomy or simple mastectomy with radiotherapy. The 5 year disease-free survival was $61 \%$ compared with $44 \%$ in historical controls. No serious side-effects were recorded. The authors concluded that significant improvement in disease-free survival could be achieved with minimal toxicity. Outline results from non-randomised studies of adjuvant tamoxifen for MBC are shown in Table 2.

In a US series of 42 men with non-metastatic breast cancer (all ER/ PR+ve); 21 received tamoxifen (50\%), 18 had chemotherapy (43\%), and 11 were irradiated [22]. After a median follow-of 8 years, the 10 year overall survival was $100 \%$ in patients in those given tamoxifen and radiation, compared with $65 \%$ for tamoxifen alone and $83 \%$ for radiation alone. Adjuvant chemotherapy in combination with Tamoxifen or used alone did not significantly improve overall survival. 


\begin{tabular}{|c|c|c|c|}
\hline Author & N & Duration & Result \\
\hline Ribeiro et al. [21] & 39 & $1-2 \mathrm{yr}$ & $61 \% 5 \mathrm{yr}$ DFS \\
\hline Zhou et al. [25] & 32 & $5 \mathrm{yr}$ & $100 \% 10 \mathrm{yr}$ OS \\
\hline Fogh et al. [22] & 42 & $5 \mathrm{yr}$ & 100 \\
\hline Xu et al. [27] & 20 & $5 \mathrm{yr}$ & $80 \% 10 \mathrm{yr}$ \\
& 99 & $<5 \mathrm{yr}$ & $50 \% 10 \mathrm{yr}$ \\
\hline
\end{tabular}

DFS = Disease-free survival OS = Overall survival

Table 2: Results of adjuvant treatment of MBC by tamoxifen.

Goss et al. [23] reported a significant increase in both disease-free and overall survival in a series involving $229 \mathrm{MBCs}$ treated in Toronto over a 40-year period. Patients in both these studies had received Tamoxifen for only 1 or 2 years and given that optimal results in women are achieved after 5 years of therapy, it is likely that the results for men are underestimated [24] In a study from China Zhou et al. [25] reported a series of $72 \mathrm{MBC}$ of whom 32 (44\%) received tamoxifen [25]. The 5 year survival of this group was $100 \%$.

Between 1999 and 2009, $126 \mathrm{MBC}$ cases were treated at the MD Anderson Hospital and of these, 64 were stage I-III, treated with tamoxifen and had at least one follow visit after tamoxifen was started [26]. A descriptive analysis of toxic effects was carried out on these 64 patients. Median age at diagnosis was 61 years and median followup after starting tamoxifen was 3.9 years (range 0.3-19.4 years). Side effects were reported by $34(53 \%)$ patients. These included weight gain $(22 \%)$ and sexual dysfunction (22\%). Treatment with tamoxifen was discontinued because of toxicity by 13 men (20\%). Problems included ocular symptoms, leg cramps, neurocognitive deficits, bone pain, sexual dysfunction, and thromboembolic events (4/64, 6\%).

Recently, $\mathrm{Xu}$ et al. [27] assessed tamoxifen adherence in relations to mortality in MBC patients. Of a cohort of 116 men diagnosed with $\mathrm{ER}+\mathrm{ve}$ disease and had been prescribed tamoxifen, only $65 \%$ were taking the agent 1 year later, reducing to $29 \%$ after 3 years and to $18 \%$ in the final year. In a multivariate analysis, significant factors for stopping tamoxifen were low social support (Hazard ratio 2.45$)$, age $(\mathrm{HR}=1.10)$, and toxicity $(\mathrm{HR}=2.19)$. For compliant patients the 10 year overall survival was $80 \%$ compared with $50 \%$ in the non-adherent group. This illustrates the urgent need to identify and deal with tamoxifen nonadherence in men.

\section{Aromatase Inhibitors}

Harris et al. used the combination of the aromatase inhibitor aminoglutethimide and hydrocortisone to treat 5 men with advanced breast cancer [28]. There was no response in the men with intact testes whereas the previously orchidectomised patient responded for 14 months. Although estrone and estradiol levels were suppressed in all patients, this was a smaller effect from that achieved by orchidectomy.

After anastrozole had been demonstrated to be superior to tamoxifen as an adjuvant therapy for postmenopausal women with ER+ve metastatic breast cancer ${ }^{[29,30]}$. Giordano et al. [31] used that aromatase inhibitor (AI) to treat 5 men with advanced disease . No clinical responses were reported: 3 patients had static disease for 4-9 months and 2 had progressive disease. As a result the MD Anderson group treated a further 2 cases of advanced MBC with a combination of letrozole and the GnRH analogue leuprolide [32]. Both cases responded to the combination whereas one had not responded to either as a single agent. Based on these encouraging results the Southwestern Oncology Group (SWOG) have started a trial S0511 in which males with metastatic ER+ve MBC are receiving anastrozole and goserelin (another LHRH analogue).
Doyen et al. [33] treated 15 men who had metastatic MBC with various aromatase inhibitors (letrozole 5, anastrozole 5, exemestane 5). Two (13\%) complete responses were reported, 4 (27\%) had partial responses, two patients (13\%) had stable disease and progression occurred in 7 (47\%) had progressive disease. E2 levels in all assessable patients $(n=6)$ undetectable during AI treatment. Among them, three had partial response, one had stable disease and two had progressive disease. There was a surge in follicle-stimulating hormone, luteinising hormone and estradiol levels in one responding patient at the time of progression.

To examine toxicity of endocrine treatment for MBC, Visram et al. conducted a review of 59 male patients treated at The Ottawa Hospital Cancer Centre between 1981 and 2003 [34]. The median age was 68.0 years. Thirty eight (64\%) received tamoxifen. $8(14 \%)$ were given anastrozole to 8 , and $5(8.5 \%)$ were treated with letrozole. Adjuvant chemotherapy was given to $10(25 \%)$.

Of the 38 men given tamoxifen, 50\% reported toxicity of which hot flushes were the most frequent problem (18\%). Five reported decreased libido, weight gain, and malaise (13.2\%). Two complained of a rash and erectile dysfunction (7.9\%). Rarer side effects included elevated liver enzymes, pulmonary embolism, superficial thrombophlebitis, myalgia, depression, visual blurring, and passage of loose stools. Nine patients (24\%) stopped tamoxifen because of toxicity.

Among those treated with anastrozole, 3 (37.5\%) reported side effects including decreased libido, leg oedema, and depression (12.5\%) but none of them stopped taking anastrozole. Two patients taking letrozole reported peripheral oedema, and another had hot flushes but no patient stopped taking letrozole.

Eggemann et al. [35] studied $257 \mathrm{MBC}$ patients with ER+ve disease from several German cancer registries of whom 207 were treated with tamoxifen and 50 with aromatase inhibitorsv. With a median followup of 42.2 months and after adjustment for the age, tumour size, nodal status, and grade. Treatment with an aromatase inhibitor was associated with a 1.5 -fold increase in risk of mortality compared with tamoxifen.

\section{LHRH Analogues}

As an alternative to surgical castration luteinising hormone releasing hormone (LHRH) analogues have been used in various ways for treatment of advanced MBC. Vorobiof and Falkson reported a case of $\mathrm{MBC}$ with pulmonary metastases successfully treated with buserelin, as an intranasal spray [36]. There was complete remission of the lung metastases but minimal toxicity.

In a larger series of 10 men with advanced breast cancer Doberauer et al. [37] administered buserelin, alone or together with flutamide (an antiandrogen), Of the 5 given buserelin alone, one had a partial remission for 12 months, extending over a further 24 months after starting flutamide. Three men had stable disease for a median of 6 months and 1 had progressive disease. For those 5 given buserelin and flutamide, 4 patients had a partial remission (median of 15 months) and one had stable disease for 12 months. Side effects included hot flushes, loss of libido, and impotence.

\section{Cyproterone Acetate}

Cyproterone acetate, a synthetic derivative of 17-hydroxyprogesterone, is an androgen receptor antagonist and also a weak progesterone receptor agonist. Lopez et al. [38] reported a $43 \%$ response rate in 11 patients with disseminated MBC given cyproterone acetate. This 
compared with 3 of 7 given tamoxifen, $2 / 5$ receiving estrogens, 2/5 given aminoglutethimide, and $0 / 3$ treated with high-dose medroxyprogesterone acetate, and 1 of 3 undergoing orchidectomy. The median overall response duration was 10 months.

In a subsequent study, Lopez combined cyproterone with the LHRH analogue buserelin to treat 11 men with recurrent or progressive MBC by total androgen blockade. They received buserelin $1500 \mu \mathrm{g}$ subcutaneously daily for one week and $600 \mu \mathrm{g}$ daily subsequently together with cyproterone acetate (CPA) $100 \mathrm{mg}$ twice daily, starting 24 hours before the first buserelin injection.

There was an objective responses in $7 / 11$ (64\%) with a median duration of 11.5 months. Stable disease for 5 months was reported in 3 patients and the median survival was 18.5 months. The main side effects were decreased or absent libido, impotence, and hot flushes. Unfortunately other groups have not explored this option for treatment of metastatic MBC.

\section{Fulvestrant}

Fulvestrant is a synthetic estrogen receptor (ER) antagonist acting as a selective ER down-regulator. Unlike tamoxifen and the aromatase inhibitors, fulvestrant binds competitively to estrogen receptors in breast cancer cells. de la Haba Rodríguez reported a single case of metastatic MBC, heavily pre-treated with chemotherapy who had a partial response after 4 months of fulvestrant with symptomatic improvement [39]. Masci et al. [40] evaluated fulvestrant in $5 \mathrm{MBC}$ patients with progressive metastatic disease and recorded one partial response, stable disease in two and progressive disease in two.

Zagouri et al. [41] treated 14 cases of metastatic MBC with fulvestrant, giving a loading dose of $500 \mathrm{mg}$ on day 1 , then $250 \mathrm{mg}$ on day 14 and monthly thereafter. All the men had received prior endocrine therapy, fulvestrant was second-line treatment in 6 , thirdline agent in 7 and fourth line in one. There were no complete response and a partial response in $3(21 \%)$ patients, with stable disease in 7 (50\%), and progressive disease in $4(29 \%)$ patients. Median time to progression was 5 months with the median overall survival being 61.5 months

\section{Conclusions}

After a multidisciplinary international meeting held at Bethesda, Maryland in September 4, 2008 it was agreed that the mainstay of systemic therapy for hormone receptor-positive MBC is hormonal therapy [42]. As has been discussed, tamoxifen is the most extensively used and studied first line therapy for both adjuvant treatment and palliation of advanced disease.

Second-line therapies include LHRH agonists, orchidectomy, estrogens, and progestins but any of these may produce psychological or physical side-effects. The role of aromatase inhibitors with or without concurrent LHRH for treatment of MBC remains undefined. There is a pressing need for large international studies with defined molecular subtyping and testing of new endocrine approaches by controlled randomised trials.

\section{References}

1. Brinton LA, Richesson DA, Gierach GL, Lacey JV Jr, Park Y, et al. (2008) Prospective evaluation of risk factors for male breast cancer. J Natl Cancer Inst 100: $1477-1481$.

2. Brinton LA, Carreon JD, Gierach GL, McGlynn KA, Gridley G (2010) Etiologic factors for male breast cancer in the U.S. Veterans Affairs medical care system database. Breast Cancer Res Treat 119: 185-192.
3. Anderson WF, Jatoi I, Tse J, Rosenberg PS (2010) Male breast cancer: a population-based comparison with female breast cancer. J Clin Oncol 28: 232239.

4. Gnerlich JL, Deshpande AD, Jeffe DB, Seelam S, Kimbuende E, et al. (2011) Poorer survival outcomes for male breast cancer compared with female breast cancer may be attributable to in-stage migration. Ann Surg Oncol 18: 18371844.

5. Miao H, Verkooijen HM, Chia KS, Bouchardy C, Pukkala E, et al. (2011) Incidence and outcome of male breast cancer: an international populationbased study. J Clin Oncol 29: 4381-4386.

6. Nahleh ZA, Srikantiah R, Safa M, Jazieh AR, Muhleman A, et al. (2007) Male breast cancer in the veterans affairs population: a comparative analysis. Cancer 109: 1471-1477.

7. Ge Y, Sneige N, Eltorky MA, Wang Z, Lin E, et al. (2009) Immunohistochemical characterization of subtypes of male breast carcinoma. Breast Cancer Res 11 R28.

8. Shaaban AM, Ball GR, Brannan RA, Cserni G, Di Benedetto A, et al. (2012) A comparative biomarker study of 514 matched cases of male and female breast cancer reveals gender-specific biological differences. Breast Cancer Res Treat 133: 949-958.

9. Sánchez-Muñoz A, Román-Jobacho A, Pérez-Villa L, Sánchez-Rovira $P$ Miramón J, et al. (2012) Male breast cancer: immunohistochemical subtypes and clinical outcome characterization. Oncology 83: 228-233.

10. Deb S, Jene N, Kconfab Investigators, Fox SB (2012) Genotypic and phenotypic analysis of familial male breast cancer shows under representation of the HER2 and basal subtypes in BRCA-associated carcinomas. BMC Cancer 12: 510.

11. Johansson I, Nilsson C, Berglund P, Lauss M, Ringnér M, et al. (2012) Gene expression profiling of primary male breast cancers reveals two unique subgroups and identifies N-acetyltransferase-1 (NAT1) as a novel prognostic biomarker. Breast Cancer Res 14: R31.

12. Kornegoor R, Verschuur-Maes $\mathrm{AH}$, Buerger $\mathrm{H}$, Hogenes $\mathrm{MC}$, de Bruin $\mathrm{PC}$ et al. (2012) Immunophenotyping of male breast cancer. Histopathology 61 $1145-1155$.

13. Nilsson C, Johansson I, Ahlin C, Thorstenson S, Amini RM, et al. (2013) Molecular subtyping of male breast cancer using alternative definitions and its prognostic impact. Acta Oncol 52: 102-109.

14. Ramantanis G, Besbeas S, Garas JG (1980) Breast cancer in the male: report of 138 cases. World J Surg 4: 621-623.

15. Muñoz de Toro MM, Maffini MV, Kass L, Luque EH (1998) Proliferative activity and steroid hormone receptor status in male breast carcinoma. J Steroid Biochem Mol Biol 67: 333-339.

16. Drahokoupilová M (2010) Metastatic breast cancer in 28 years old man. Klin Onkol 23: 264-268

17. Fentiman IS, Fourquet A, Hortobagyi GN (2006) Male breast cancer. Lance 367: 595-604.

18. Beatson GT (1896) On the treatment of inoperable cases of carcinoma of the mamma: suggestions for a new method of treatment, with illustrative cases. Lancet 2:104.

19. Kantarjian H, Yap HY, Hortobagyi G, Buzdar A, Blumenschein G (1983) Hormonal therapy for metastatic male breast cancer. Arch Intern Med 143: 237-240.

20. Cantwell BM, Tong D, Minton M, Rubens RD, Hayward JL (1978) Tamoxifen and male breast cancer. Lancet 2: 582-583.

21. Ribeiro G, Swindell R (1992) Adjuvant tamoxifen for male breast cancer (MBC) $\mathrm{Br} J$ Cancer 65: 252-254.

22. Fogh S, Hirsch AE, Langmead JP, Goldberg SI, Rosenberg CL, et al. (2011) Use of tamoxifen with postsurgical irradiation may improve survival in estrogen and progesterone receptor-positive male breast cancer. Clin Breast Cancer 11 $39-45$

23. Goss PE, Reid C, Pintilie M, Lim R, Miller N (1999) Male breast carcinoma: review of 229 patients who presented to the Princess Margaret Hospital during 40 years: 1955-1996. Cancer 85: 629-639.

24. Nordenskjöld B, Rosell J, Rutqvist LE, Malmström PO, Bergh J, et al. (2005) Coronary heart disease mortality after 5 years of adjuvant tamoxifen therapy: results from a randomized trial. J Natl Cancer Inst 97: 1609-1610. 
25. Zhou FF, Xia LP, Wang X, Guo GF, Rong YM, et al. (2010) Analysis of prognostic factors in male breast cancer: a report of 72 cases from a single institution. Chin J Cancer 29: 184-188.

26. Pemmaraju N, Munsell MF, Hortobagyi GN, Giordano SH (2012) Retrospective review of male breast cancer patients: analysis of tamoxifen-related sideeffects. Ann Oncol 23: 1471-1474.

27. Xu S, Yang Y, Tao W, Song Y, Chen Y, et al. (2012) Tamoxifen adherence and its relationship to mortality in 116 men with breast cancer. Breast Cancer Res Treat 136: 495-502.

28. Harris AL, Dowsett M, Stuart-Harris R, Smith IE (1986) Role of aminoglutethimide in male breast cancer. $\mathrm{Br} \mathrm{J}$ Cancer 54: 657-660.

29. Bonneterre J, Thürlimann B, Robertson JF, Krzakowski M, Mauriac L, et al. (2000) Anastrozole versus tamoxifen as first-line therapy for advanced breast cancer in 668 postmenopausal women: results of the Tamoxifen or Arimidex Randomized Group Efficacy and Tolerability study. J Clin Oncol 18: 3748-3757.

30. Nabholtz JM, Buzdar A, Pollak M, Harwin W, Burton G, et al. (2000) Anastrozole is superior to tamoxifen as first-line therapy for advanced breast cancer in postmenopausal women: results of a North American multicenter randomized trial. Arimidex Study Group. J Clin Oncol 18: 3758-3767.

31. Giordano SH, Valero V, Buzdar AU, Hortobagyi GN (2002) Efficacy of anastrozole in male breast cancer. Am J Clin Oncol 25: 235-237.

32. Giordano SH, Hortobagyi GN (2006) Leuprolide acetate plus aromatase inhibition for male breast cancer. J Clin Oncol 24: e42-43.

33. Doyen J, Italiano A, Largillier R, Ferrero JM, Fontana X, et al. (2010) Aromatase inhibition in male breast cancer patients: biological and clinical implications. Ann Oncol 21: 1243-1245.
34. Visram H, Kanji F, Dent SF (2010) Endocrine therapy for male breast cancer: rates of toxicity and adherence. Curr Oncol 17: 17-21.

35. Eggemann H, Ignatov A, Smith BJ, Altmann U, von Minckwitz G, et al. (2013) Adjuvant therapy with tamoxifen compared to aromatase inhibitors for 257 male breast cancer patients. Breast Cancer Res Treat 137: 465-470.

36. Vorobiof DA, Falkson G (1987) Nasally administered buserelin inducing complete remission of lung metastases in male breast cancer. Cancer 59: 688689 .

37. Doberauer C, Niederle N, Schmidt CG (1988) Advanced male breast cance treatment with the LH-RH analogue buserelin alone or in combination with the antiandrogen flutamide. Cancer 62: 474-478

38. Lopez M, Di Lauro L, Lazzaro B, Papaldo P (1985) Hormonal treatment of disseminated male breast cancer. Oncology 42: 345-349.

39. de la Haba Rodríguez JR, Porras Quintela I, Pulido Cortijo G, Berciano Guerrero M, Aranda E (2009) Fulvestrant in advanced male breast cancer. Ann Oncol 20: 1896-1897.

40. Masci G, Gandini C, Zuradelli M, Pedrazzoli P, Torrisi R, et al. (2011) Fulvestrant for advanced male breast cancer patients: a case series. Ann Oncol 22: 985.

41. Zagouri F, Sergentanis TN, Chrysikos D, Zografos E, Rudas M, et al. (2013) Fulvestrant and male breast cancer: a case series. Ann Oncol 24: 265-266.

42. Korde LA, Zujewski JA, Kamin L, Giordano S, Domchek S, et al. (2010) Multidisciplinary meeting on male breast cancer: summary and research recommendations. J Clin Oncol 28: 2114-2122.
This article was originally published in a special issue, Hormonal Therapy handled by Editors. Dr. Ratna K Vadlamudi, University of Texas San Antonio, TX, USA; Dr. Baharudin Bin Abdullah, School of Medical Sciences, Health Campus USM, Malaysia 